\title{
Erratum to: Prospective, long-term study of the effect of cabergoline on valvular status in patients with prolactinoma and idiopathic hyperprolactinemia
}

Laurent Vroonen $^{1}$ Patrizio Lancellotti ${ }^{2}$ Monica Tomé Garcia ${ }^{1}$ Raluca Dulgheru ${ }^{2}$. Matilde Rubio-Almanza $^{1}$ - Ibrahima Maiga ${ }^{1}$. Julien Magne $^{2}$ - Patrick Petrossianss ${ }^{1}$. Renata Auriemma $^{1} \cdot$ Adrian F. Daly $^{1} \cdot$ Albert Beckers $^{1}$

Published online: 16 November 2016

(C) Springer Science+Business Media New York 2016

\section{Erratum to: Endocrine} DOI 10.1007/s12020-016-1120-5

In the original publication, one of the co-author's name was incorrectly published as Matilde Almanza instead of Matilde Rubio-Almanza. The author's name is corrected with this erratum.

The online version of the original article can be found at doi:10.1007/ s12020-016-1120-5.

Albert Beckers

albert.beckers@chu.ulg.ac.be

1 Department of Endocrinology, Center Hospitalier Universitaire de Liège, University of Liège, Domaine Universitaire du Sart-Tilman, Liège 4000, Belgium

2 Department of Cardiology, Center Hospitalier Universitaire de Liège, University of Liège, Domaine Universitaire du Sart-Tilman, Liège 4000, Belgium 